\title{
Adverse effects of captopril in hospital outpatients with hypertension
}

\author{
T. Walley, P. Winstanley, D. Roberts, M. Grimmer, M. Orme and \\ A. Breckenridge
}

Department of Pharmacology and Therapeutics, University of Liverpool, Ashton Street, P.O. Box 147, Liverpool L69 3BX, UK.

\begin{abstract}
Summary: Hypertensive patients prescribed captopril while attending a hospital hypertension clinic were studied, to identify the benefits of the drug, its adverse effects and factors predisposing to them. One hundred and eighty two patients were followed for a mean of 18 months; 24 received captopril alone, and 158 combinations of captopril and other antihypertensive drugs, especially loop diuretics (91/158), or thiazide diuretics $(57 / 158)$, or other vasodilators $(57 / 158)$. The mean final dose of captopril was $67 \mathrm{mg} /$ day.

Blood pressure (BP) was effectively controlled in $73 \%$ of patients (mean fall in systolic BP $29 \mathrm{mmHg}$, CI 24 to 34, $P \leqslant 0.001$; mean fall in diastolic BP $18 \mathrm{mmHg}, C I 16$ to 20, $P \leqslant 0.001$ ). Blood urea and creatinine rose slightly in all patients (urea by $0.9 \mathrm{mmol} / \mathrm{l}[13 \%], \mathrm{CI} 0.5-1.3, P \leqslant 0.001$ and creatinine by $9 \mu \mathrm{mol} / 1[8 \%], C I 4-13, P \leqslant 0.001)$. Twenty six patients were withdrawn from captopril therapy: 6 because of poor control of their blood pressure, two because it was no longer necessary and $12(7.7 \%)$ because of extrarenal adverse effects - 10 for rashes, one each for gastric upset and impotence. Captopril was withdrawn in a further 6 patients, because of deteriorating renal function. Factors discriminating those at risk of renal dysfunction were high doses of captopril, concomitant high dose diuretic therapy and undiagnosed renovascular disease.
\end{abstract}

\section{Introduction}

Captopril and other angiotensin converting enzyme (ACE) inhibitors are at present limited to use as second line therapy in hypertension. Although undoubtedly effective, their use as first line agents is controversial because of their adverse effects, in particular, renal dysfunction. ${ }^{1}$ If the ACE inhibitors are to be more widely used, factors predisposing patients to the adverse effects must be better understood.

Patients referred to hospital for control of hypertension differ from those regularly managed by general practitioners alone, either because their hypertension is more difficult to control, or they have already suffered adverse effects on antihypertensive agents or they have other complicating diseases. While post-marketing surveillance in general practice has shown captopril to be an effective antihypertensive agent, ${ }^{2}$ few large studies have considered the use of captopril for hypertension in hospital outpatients. We studied the use of captopril in hypertensive patients attending a secondary and tertiary referral clinic, to determine its benefits, adverse effects and how these might be predicted.

Correspondence: T. Walley M.R.C.P.

Accepted: 5 September 1989

\section{Methods}

From 1st January 1982 to 31st December 1987, data was collected on all patients first prescribed captopril while attending a hypertension clinic. Patients attended at 2-6 monthly intervals thereafter, until discharged back to their general practitioner's care when their blood pressure was stable. At each patient visit, specified symptoms (e.g. rash, taste disturbance) and spontaneously volunteered symptoms were recorded in a standardized manner to assess adverse effects, especially any which required drug withdrawal. Blood pressure was recorded after the patient had rested supine for five minutes, using Korotkoff phase $\mathrm{V}$ for diastolic. Biochemical and haematological indices were checked before treatment and at 6 monthly intervals afterwards. Data were recorded on a personal computer. For the current report, data from the patient's visit before captopril administration, and last visit while taking captopril were analysed. Patients on whom data was recorded at only one visit were excluded.

Statistical analysis was by Mann Whitney $U$ test for nonparametric paired data and $\chi^{2}$ analysis. Results are shown as mean (s.d.). 


\section{Results}

One hundred and ninety eight patients were prescribed captopril during the study period. Sixteen of these were excluded because they had only attended the clinic once. From information received from their general practitioners, only one of the 16 was known to have stopped captopril because of an adverse reaction (rash). Data on 182 patients (aged 55 [11] yrs, range 20-90, 102 male and 80 female) were analysed. The mean duration of follow up was 18 (14) months. The indications for treatment with captopril were as follows: in 99, because hypertension was uncontrolled on other agents, in 19 because the patients had suffered adverse effects on other drugs despite adequate blood pressure control, and in 64 because of thiazide resistant hypertension and other complicating conditions such as peripheral vascular disease or chronic obstructive lung disease which precluded the use of some other antihypertensive agents. The mean initial dose of captopril was 64 (51) $\mathrm{mg} /$ day and the final dose was 67 (46) $\mathrm{mg}$ /day (range $12.5-300 \mathrm{mg} /$ day).

Captopril was used as monotherapy in 24 patients $(13 \%)$, in combination with one other drug in $90(47 \%)$, and with two or more other drugs in $68(37 \%)$. The most widely used combinations were captopril with the loop diuretics frusemide or bumetamide ( 91 patients, $50 \%$ ), or captopril with thiazide diuretics (57 patients, $31 \%)$. Other vasodilators ( 57 patients, $31 \%$ ), especially nifedipine, or beta blockers ( 33 patients, $18 \%$ ) were used as part of triple therapy.

\section{Efficacy}

Captopril, either alone or in combination, lowered blood pressure from $183(37) / 110(19) \mathrm{mmHg}$, to
154(27)/92(14) $\mathrm{mmHg}$ (mean difference in systolic BP $29 \mathrm{mmHg}, 95 \%$ CI 24 to $34, P \leqslant 0.001$, and for diastolic BP $18 \mathrm{mmHg}, 95 \%$ CI 16 to 20 , $P \leqslant 0.001)$. However, 49 patients $(27 \%$, all on combination therapy) were considered to have inadequate control of their blood pressure (BP $>160 / 95 \mathrm{mmHg}$ ) at the last clinic assessment.

\section{Adverse effects}

Effects on renal function There was a rise in both urea and creatinine during captopril therapy (Table I). This was not related to concomitant diuretic therapy, as similar rises in urea $(14 \%)$ and creatinine $(8 \%)$ were seen regardless of therapy with loop diuretics, thiazide diuretics or no diuretics (Table I). These rises were only statistically significant in the group of patients on diuretic therapy, but this is due to the number of patients in each group (34 on no diuretics and 91 and 57 on loop and thiazide diuretics respectively). The changes were not clinically significant, except in 6 patients $(3 \%$, all male) who had seriously deteriorating renal function and who had to discontinue captopril (Table II).

Proteinuria Eight patients developed proteinuria (more than trace on dipstick). One patient (no. 5 in Table II), developed the nephrotic syndrome (proteinuria $>12 \mathrm{~g} /$ day). Renal biopsy showed only hypertensive nephrosclerotic changes. The nephrotic syndrome resolved when captopril was discontinued, but 2 years later this patient still had significant proteinuria (1-2 g/day). In the other patients, the proteinuria was mild and did not require cessation of treatment.

Table I Biochemical changes in 182 patients before and after taking captopril (C) for hypertension, divided on the basis of their concurrent diuretic therapy. Mean (s.d.)

\begin{tabular}{lcccc}
\hline & C; no diuretics & $\begin{array}{l}C+\text { loop } \\
\text { diuretics }\end{array}$ & $C+$ thiazides & All \\
\hline Number & 34 & 91 & 57 & 182 \\
Urea mmol/1 & & & & \\
$\quad$ Before & $5.5(2.3)$ & $6.8(4.2)$ & $6.0(2.3)$ & $6.4(2.3)$ \\
After & $5.9(2.7)$ & $7.8(4.1)$ & $6.9(3.1)$ & $7.2(3.7)$ \\
Difference & $0.4(3.1)$ & $1.0(3.33)$ & $0.9(1.9)$ & $0.9(2.9)$ \\
$95 \%$ CI & $-0.4-1.4$ & $0.3-1.7$ & $0.3-1.4$ & $0.5-1.3$ \\
$P$ & $>0.5$ & $\leqslant 0.01$ & $\leqslant 0.005$ & $\leqslant 0.001$ \\
Creatinine $\mu$ mol/1 & & & & \\
$\quad$ Before & $108(32)$ & $117(52)$ & $105(34)$ & $112(45)$ \\
After & $118(52)$ & $126(61)$ & $114(55)$ & $121(58)$ \\
Difference & $10(52)$ & $9(31)$ & $9(27)$ & $9(33)$ \\
(95\% CI) & $-7-27$ & $2-16$ & $2-16$ & $4-13$ \\
$P$ & $>0.1<0.5$ & $\leqslant 0.01$ & $\leqslant 0.05$ & $\leqslant 0.001$ \\
\hline
\end{tabular}


Table II Patients withdrawn from captopril therapy because of deteriorating renal function

\begin{tabular}{|c|c|c|c|c|c|c|c|c|}
\hline & $\begin{array}{c}\text { Age } \\
\text { (years) }\end{array}$ & $\begin{array}{c}\text { Dose } \\
\text { (mg/day) }\end{array}$ & $\begin{array}{l}\text { Duration } \\
\text { (months) }\end{array}$ & $\begin{array}{c}\text { Urea } \\
(\mathrm{mmol} / \mathrm{l})\end{array}$ & $\begin{array}{l}\text { Initial } \\
\text { Creatinine } \\
\quad(\mu \mathrm{mol} / l)\end{array}$ & Urea & $\begin{array}{l}\text { Final } \\
\text { Creatinine }\end{array}$ & Comment \\
\hline 1. & 48 & 100 & 16 & 15.8 & 279 & 19.1 & 343 & $\begin{array}{l}\text { On loop diuretics Pre- } \\
\text { existing glomerulonephritis }\end{array}$ \\
\hline 2. & 54 & 25 & 18 & 6.4 & 98 & 12.9 & 176 & $\begin{array}{l}\text { Diabetes mellitus. Re- } \\
\text { current urinary tract } \\
\text { infections. No diuretics. }\end{array}$ \\
\hline 3. & 66 & 75 & 6 & 7.0 & 129 & 14.0 & 157 & $\begin{array}{l}\text { Unilateral RAS- on } \\
\text { thiazides- now on other } \\
\text { medical therapy. }\end{array}$ \\
\hline 4. & 49 & 150 & 14 & 6.1 & 116 & 10.2 & 310 & $\begin{array}{l}\text { Bilateral RAS. Also on } \\
\text { loop diuretics. Renal } \\
\text { function returned to } \\
\text { normal when captopril was } \\
\text { discontinued. }\end{array}$ \\
\hline 5. & 49 & 75 & 27 & 6.8 & 122 & 14.4 & 216 & $\begin{array}{l}\text { On loop diuretics } \\
\text { Nephrotic syndrome? due } \\
\text { to captopril }\end{array}$ \\
\hline 6. & 57 & 150 & 48 & 5.9 & 135 & 22.4 & 202 & $\begin{array}{l}\text { On loop diuretics. Renal } \\
\text { function improved with } \\
\text { reduction of diuretics. }\end{array}$ \\
\hline Mean & 54 & 96 & 22 & 8.0 & 147 & $15.5^{*}$ & $234^{*}$ & \\
\hline s.d. & 7 & 48 & 15 & 3.5 & 60 & 4.5 & 75 & \\
\hline
\end{tabular}

RAS $=$ Renal artery stenosis. ${ }^{*} P<0.05$

Other withdrawals and adverse effects Twenty other patients stopped captopril, six because of poorly controlled hypertension and two because it was no longer thought necessary in the control of their hypertension. Twelve $(6.6 \%, 5$ female, mean age 55 [12] years) stopped captopril because of extrarenal adverse effects (10 rashes, and one each because of gastrointestinal upset and impotence). The mean captopril dose at the time of withdrawal was $97(83) \mathrm{mg} /$ day $(P<0.05$ compared to all patients), and the mean duration of treatment 12 (14) months. Four of the 38 patients over 65 at the time they started captopril treatment withdrew because of renal and extra renal adverse effects, an incidence of $10 \%$ compared to $5.5 \%$ in those under $65\left(\chi^{2}=0.42\right.$, not statistically significant).

One patient died from a perforated peptic ulcer while taking captopril. No patient suffered from neutropenia during captopril therapy (initial mean white cell count was $8.2[2.3] \times 10^{9} / 1$, and the last count was $8.0(2.3) \times 10^{9} / 1$, not significant). One patient complained of taste disturbance. No patient complained of cough.

\section{Discussion}

Previous studies of captopril in hypertensive patients found that adverse effects required drug withdrawal in $7.2-8.5 \% .^{2,3}$ The incidence of drug withdrawal because of extrarenal adverse effects
$(7.7 \%)$ in the present study is therefore similar $\left(\chi^{2}=0.2, P>0.5\right)$.

Blood urea and serum creatinine rose after the patients studied started captopril. In most, the changes were minor and not clinically important. Since there is no control group in this study, we cannot say whether the changes in renal function are the result of captopril or other therapy, or part of the natural history of these patient's hypertension. A recent similar retrospective study found that over a mean of 5 years and regardless of the quality of blood pressure control or drug therapy, $85 \%$ of hypertensive patients had rises in serum creatinine of $3-8 \% .{ }^{4}$ This is similar to that seen in our patients and suggests that such a rise in creatinine is part of the natural history of hypertension and not a captopril effect.

The major difference between the current and previous studies ${ }^{2,3}$ is the rate of renal dysfunction requiring captopril withdrawal $(3 \%$ vs $0.13 \%$, $\left.\chi^{2}=88.07, P \leqslant 0.001\right)$. The most likely explanation for this lies in the differing populations studied, that is community versus hospital based. Rostand et al. ${ }^{4}$ found that $15 \%$ of similar hypertensive hospital outpatients developed gradually deteriorating renal function (serum creatinine rising by $>35 \mu \mathrm{mol}$ ) over 5 years, but in only $1 \%$ was the deterioration clinically significant.

In two of our cases (nos. 1 and 2 in Table II), captopril was probably responsible for the deterioration in renal function. Patient 1 had glomerulo- 
nephritis of unknown aetiology with deteriorating renal function, possibly due to his hypertension. Captopril was given to improve blood pressure control. Although his blood pressure fell from $180 / 120$ to $160 / 96 \mathrm{mmHg}$, he still required long term dialysis. In patient 2 , deterioration was probably due to diabetes mellitus and recurrent urinary tract infections. In two further cases (nos. 3 and 4), the use of captopril exposed renal artery stenosis, previously unsuspected. In the last two cases (nos. 5 and 6), no cause other than the antihypertensive medication was found to account for the changes in renal function. Patient 5 had the nephrotic syndrome; captopril has been previously associated with the nephrotic syndrome and membranous glomerulonephritis on biopsy. ${ }^{5}$ However, similar histological changes are found in biopsies from hypertensive patients not on captopril. ${ }^{6}$ Renal biopsy in the patient reported here was unhelpful.

In patient 6 , the deterioration in the renal indices may be related as much to diuretics (frusemide $120 \mathrm{mg} /$ day) as to captopril. The combination of diuretics and captopril is very effective in treating hypertension. ${ }^{1}$ But when there is diuretic-induced sodium depletion, blocking the renin-angiotensin system by captopril may severely reduce glomerular filtration rate and affect renal function. ${ }^{7}$ Captopril alone is less likely to cause similar problems. ${ }^{8}$ It is of interest therefore that 5 of the 6 patients with renal deterioration (all but no. 2) were also taking diuretics. There was no relationship

\section{References}

1. Breckenridge, A.M. Angiotensin converting enzyme inhibitors. $\mathrm{Br}$ Med J 1988, 296: 618-620.

2. Chalmers, D., Dombey, S.L. \& Lawson, D.H. Post marketing surveillance of captopril (for hypertension): a preliminary report. Br J Clin Pharmacol 1987, 24: 343-349.

3. Frohlich, E.D., Cooper, R.A. \& Lewis, E.J. Review of the overall experience of captopril in hypertension. Arch Intern Med 1984, 144: 1441-1444.

4. Rostand, S.G., Brown, G., Kirk, K.A., Rutsky, E.A. \& Dunstan, H.P. Renal insufficiency in treated essential hypertension. $N$ Engl J Med 1989, 320: 684-688.

5. Prins, E.J.L., Hoorntje, S.J., Weening, J.J. \& Donker, A.J.M Nephrotic syndrome in a patient on captopril. Lancet 1979, ii: 306. between blood pressure and the risk of severe adverse renal effects, suggesting that these adverse effects were not mediated by hypotension or hypertension alone.

Some of the extrarenal adverse effects described were probably not captopril-related; for instance, captopril is not known to cause impotence. There were no complaints of unproductive cough, due partly to our failure to incorporate cough in 1981 as one of the symptoms for which specific inquiry was made in the standardized data collection.

Patients who suffered adverse effects, both renal and extrarenal, were taking higher than average doses, implying that adverse effects are dose related, but in the case of the renal adverse effects, this may also reflect the higher doses used to control hypertension in these patients.

The risk factors therefore associated with captopril-induced renal dysfunction in this study include high doses of captopril, high doses of diuretics, and undiagnosed renovascular disease. The duration of captopril therapy before the emergence of these adverse effect (6-48 months) underlines the need to monitor renal function regularly in all patients throughout their treatment with this drug.

\section{Acknowledgement}

This study was supported by Squibb UK.

6. Captopril Collaborative Study Group. Does captopril cause renal damage in hypertensive patients? Lancet 1982, i: 988-990.

7. Hricik, D.E. Captopril induced renal insufficiency and the role of sodium balance. Ann Intern Med 1985, 103: 222-223.

8. Watson, M.L., Bell, G.M., Muir, A.L., Buist, T.A.S., Kellett, R.J. \& Padfield, P.L. Captropril/diuretic combinations in severe renovascular disease: a cautionary note. Lancet 1983, ii: 404-405. 